\title{
Curcumin inhibits cell proliferation and promotes apoptosis of laryngeal cancer cells through Bcl-2 and PI3K/Akt, and by upregulating miR-15a
}

\author{
SHAOFENG MOU ${ }^{1}$, ZHONGXIN ZHOU ${ }^{1}$, YUKAI HE ${ }^{2}$, FUXING LIU ${ }^{1}$ and LILI GONG ${ }^{1}$ \\ Departments of ${ }^{1}$ Otolaryngology and ${ }^{2}$ Infection, Liaocheng City People's Hospital, Liaocheng, Shandong 252000, P.R. China
}

Received September 2, 2015; Accepted January 26, 2017

DOI: 10.3892/ol.2017.6739

\begin{abstract}
Curcumin is a natural compound extracted from the dried rhizomes of Curcuma (curcuma root or zedoary) that exhibits extensive pharmacological effects and low toxicity. The aim of the present study was to investigate whether curcumin inhibits cell proliferation and promotes apoptosis of laryngeal cancer through $\mathrm{Bcl}-2$ and phosphoinositide 3-kinase (PI3K)/protein kinase B (Akt), and by upregulating microRNA-15a (miR-15a). It was demonstrated that curcumin inhibits cell proliferation, and promotes apoptosis and increased caspase-3 activity of human laryngeal cancer cells. Furthermore, curcumin decreased $\mathrm{Bcl}-2$ and $\mathrm{PI} 3 \mathrm{~K}$ protein expression, and decreased the phospho (p)-Akt protein expression of human laryngeal cancer cells. Furthermore, curcumin activated miR-15a expression by human laryngeal cancer cells. Suppression of miR-15a expression reversed the anticancer effect of curcumin on cell proliferation of human laryngeal cancer cells and increased Bcl-2 and PI3K/Akt protein expression in AMC-HN-8 cells treated with $40 \mu \mathrm{M}$ of curcumin. The results of the present study suggest that curcumin inhibits cell proliferation and promotes apoptosis of laryngeal cancer cells through $\mathrm{Bcl}-2$ and PI3K/Akt, and by upregulating miR-15a.
\end{abstract}

\section{Introduction}

Head and neck carcinoma is a major type of cancer that causes mortality in humans, ranking sixth in the incidence rate of all types of cancer (1). Laryngeal cancer is one of the most common types of head and neck carcinoma, ranking second in the incidence rate of all respiratory tract neoplasms behind head and neck squamous cell carcinoma, which accounts for 95\% of all types of head and neck carcinoma (2). Concomitant with increased industrialization and the exacerbation of air

Correspondence to: Ms. Lili Gong, Department of Otolaryngology, Liaocheng City People's Hospital, 67 West Dongchang Road, Liaocheng, Shandong 252000, P.R. China

E-mail: gongllsd@yeah.net

Key words: curcumin, laryngeal cancer, apoptosis regulator Bcl-2, phosphoinositide 3-kinase/protein kinase B, microRNA-15a pollution, the incidence of laryngeal cancer is increasing by $25 \%$ /year, primarily in middle aged and elderly males (3). In 2008, the incidence of laryngeal cancer was 5.1/100,000 estimated in male patients around the world, and the mortality rate was $\sim 2.2 / 100,000$ (4). In spite of novel surgical methods, novel chemotherapeutic drugs and advanced radiation therapy in the treatment of laryngeal cancer in the last 30 years, the overall survival rate of patients with laryngeal cancer has not improved; instead, ithas exhibited a downward trend, with a survival rate of $\sim 50 \%$, and a survival rate of $<40 \%$ for patients with advanced laryngeal cancer (3).

Early diagnosis of laryngeal cancer and improvementsin effective treatment are required to improve our understanding of the underlying molecular mechanism of the development of laryngeal cancer, thereforenovel or early treatment may be developed (5). Epidemiological investigation has confirmed that the etiology of laryngeal cancer includes smoking, alcohol consumption, air pollution and occupational factors (6). With the development of molecular biology techniques, it has beendemonstrated that the development of laryngeal cancer involves phosphoinositide 3-kinase (PI3K)/protein kinase B (Akt), apoptosis regulator $\mathrm{Bcl}-2$, c-Myc proto-oncogene protein, epidermal growth factor receptor and other oncogenes (7). Each microRNA (miRNA/miR) is considered to be able to regulate hundreds of genes and has disease-dependency, tissue-specificity and expression stability. In numerous diseases, the expression profile of miRNAshave certain characteristic alterations, particularly in the tumor; the expression of miRNAs in tumor tissues and adjacent wild-type tissues was significantly different (8). It has been demonstrated that analysis of miRNA levels in different tumors can assist with early diagnosis and evaluation of prognosis (9). miRNAs are emerging as molecular markers for the diagnosis, recurrence, metastasis and prognosis of numeroustypes of malignant tumor (9).

Curcumin, a polyphenolic compound (Fig. 1) of relatively low molecular mass, was initially isolated from Curcuma longa in 1870 (10). In 1910, following the elucidation of the chemical structure of double feruloyl methane, research into the physiological and pharmacological effects of curcumin made marked progress (11). Curcumin has been demonstrated to exhibit anti-inflammatory, antioxidant, lipid-lowering, antivirus, anti-infection, anti-tumor, anti-liver fibrosis and anti-atherosclerosis effects, in addition to other pharmacological activity; 
furthermore, curcumin demonstrates low toxicity without serious adverse reactions $(11,12)$. It has been demonstrated that the underlying molecular mechanism of the anti-tumor effects of curcumin primarily involves apoptosis of tumor cells, inhibition of the signal transduction pathway of tumor cell growth, oxidationresistance and inhibition of tumor angiogenesis (13). In the present study, it was identified that curcumin inhibits cell proliferation and promotes apoptosis of laryngeal cancer through a novel mechanism involving altered regulation of Bcl-2- and PI3K/Akt-targeting miRNAs.

\section{Materials and methods}

Cell culture. Laryngeal squamous cell carcinoma cell line AMC-HN-8 was purchased from Shanghai Institute Chinese Academy of Sciences (Shanghai, China) and cultured with Dulbecco's modified Eagle's medium (Invitrogen; Thermo Fisher Scientific, Inc., Waltham, MA, USA) and 10\% fetal bovine serum (Invitrogen; Thermo Fisher Scientific, Inc.), supplemented with $100 \mu \mathrm{M}$ penicillin and $100 \mu \mathrm{M}$ streptomycin at $37^{\circ} \mathrm{C}$ in a humidified atmosphere containing $5 \% \mathrm{CO}_{2}$.

MTT assay. AMC-HN-8 cells [(1.0-2.0) $\times 10^{4}$ cells/well] were cultured in 96-well plates with 0,20 and $40 \mu \mathrm{M}$ of curcumin at $37^{\circ} \mathrm{C}$ in a humidified atmosphere containing $5 \% \mathrm{CO}_{2}$ for 0-3 days. A 50- $\mu 1$ volume of $5 \mathrm{mg} / \mathrm{ml}$ MTT dye (Sigma-Aldrich; Merck Millipore, Darmstadt, Germany) was added to each well and incubated for $4 \mathrm{~h}$. Subsequently, $150 \mu \mathrm{l}$ of dimethylsulfoxide (Invitrogen; Thermo Fisher Scientific, Inc.) was added to each well prior to agitation for $20 \mathrm{~min}$. The optical density of samples was determined at $490 \mathrm{~nm}$ using a Versamax microplate reader (Molecular Devices, LLC, Sunnyvale, CA, USA).

Flow cytometric detection of apoptosis. AMC-HN-8 cells [(1.0-2.0) $\times 10^{6}$ cells/well] were cultured in 6-well plates with 0 , 10,20 and $40 \mu \mathrm{M}$ curcumin at $37^{\circ} \mathrm{C}$ in a humidified atmosphere containing $5 \% \mathrm{CO}_{2}$ for 1 day. AMC-HN-8 cells were washed twice with ice-cold PBS prior to being harvested. AMC-HN-8 cells $\left(1 \times 10^{6}\right.$ cells) were resuspended with $1 \mathrm{X}$ binding buffer and stained with $5 \mu \mathrm{l}$ Annexin V-fluorescein isothiocyanate for $30 \mathrm{~min}$ in darkness at $4^{\circ} \mathrm{C}$. A $10-\mu 1$ volume of propidium iodide was added to each well and apoptosis was analyzed using flow cytometry (BD C6 flow cytometer; BD Biosciences, Franklin Lakes, NJ, USA).

Western blot analysis of cell lysates. AMC-HN-8 cells [(1.0-2.0) $\times 10^{6}$ cells/well] were cultured in 6-well plates with $0,10,20$ and $40 \mu \mathrm{M}$ curcumin at $37^{\circ} \mathrm{C}$ in a humidified atmosphere containing $5 \% \mathrm{CO}_{2}$ for 1 day. AMC-HN-8 cells were lysed in $1 \mathrm{ml}$ radioimmunoprecipitation assay lysis buffer (Beyotime Institute of Biotechnology, Haimen, China) and harvested. Following centrifugation at $12,000 \mathrm{x}$ g for $10 \mathrm{~min}$ at $4^{\circ} \mathrm{C}$, the supernatant was collected and proteins were quantified using a bicinchoninic acid assay (Beyotime Institute of Biotechnology) according to the manufacturer's protocol. Total protein $(\sim 50 \mu \mathrm{g} /$ lane $)$ was separated by $10 \%$ SDS-PAGE and transferred onto a $0.22 \mu \mathrm{m}$ pore size nitrocellulose membrane (Sigma-Aldrich; Merck Millipore). The nitrocellulose membrane was incubated with anti-Bcl-2 (cat. no. sc-509; dilution, 1:1,000), anti-PI3K (cat. no. sc-293172; dilution, 1:200),

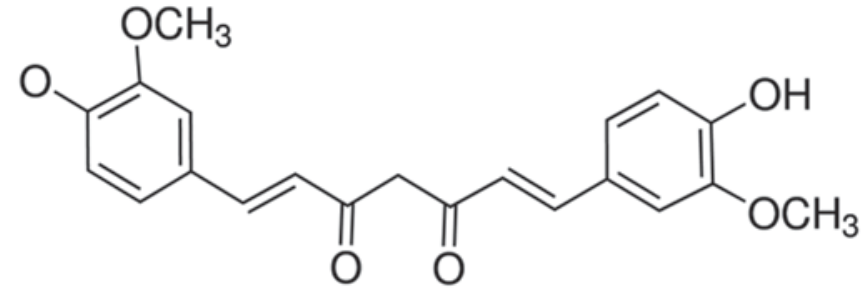

Figure 1. Chemical structure of curcumin.

anti-phosphorylated (p)-Akt (cat. no. sc-7985-R; dilution, 1:300), anti-Akt (cat. no. sc-8312; dilution, 1:300; all from Santa Cruz Biotechnology, Inc., Dallas, TX, USA) and anti- $\beta$-actin (cat. no. sc-70319; dilution, 1:500; Sangon Biotech Co., Ltd., Shanghai, China) antibodies overnight at $4^{\circ} \mathrm{C}$ subsequent to blocking in Tris-buffered saline containing $0.1 \%$ Tween-20 (TBST) with 5\% dried skimmed milk at room temperature for $1 \mathrm{~h}$. The nitrocellulose was incubated with anti-mouse or anti-rabbit secondary antibodies (cat. nos. sc-2005 and sc-2357, respectively; dilution, 1:1,000; Santa Cruz Biotechnology, Inc.) at $37^{\circ} \mathrm{C}$ for $1 \mathrm{~h}$, detected using enhanced chemiluminescence reagent (Thermo Fisher Scientific, Inc., USA) subsequent to washing with TBST, and analyzed using Quantity One software 3.0 (Bio-Rad Laboratories, Inc., Hercules, CA, USA). The whole procedure was repeated three times.

Reverse transcription-quantitative polymerase chain reaction (RT-qPCR). AMC-HN-8 cells [(1.0-2.0)x $10^{6}$ cells/well] were cultured in 6-well plates with $0,10,20$ and $40 \mu \mathrm{M}$ curcumin at $37^{\circ} \mathrm{C}$ in a humidified atmosphere containing $5 \% \mathrm{CO}_{2}$ for 1 day. Total RNA was extracted using $\mathrm{TRIzol}^{\circledR}$ reagent (Invitrogen; Thermo Fisher Scientific, Inc.) and reverse-transcribed into cDNA using a TaqMan MicroRNA Reverse Transcription kit (Applied Biosystems; Thermo Fisher Scientific, Inc.), according to the manufacturer's protocol. qPCR was performed on $1.0 \mu \mathrm{l}$ cDNA using a TaqMan MicroRNA assay (Applied Biosystems; Thermo Fisher Scientific, Inc.), according to the manufacturer's protocol (including thermocycler settings), with the following primers: miR-15a forward, 5'-GCTAGC AGCACATAATGGTTTGTG-3' and reverse, 5'-GTGCAG GGTCCGAGGTATTC-3'; U6 small nuclear ribonucleoprotein forward, 5'-GTGCAGGGTCCGAGGTATTC-3' and reverse, 5'-AACGCTTCACGAATTTGCGT-3'. The $2^{-\Delta \Delta C q}$ method was used for quantification (14).

Anti-miRNA-15a and cell transfection. Anti-miRNA-15a (sequence, 5'-TCATGGCAGCCTGGTCTACATGG-3') and negative control (NC; sequence, 5'-CCCCCCCCCCCCCC-3') oligonucleotides were synthesized by Shanghai GenePharma Co., Ltd. (Shanghai, China) and were transfected into AMC-HN-8 cells at $100 \mathrm{nM}$ using Lipofectamine ${ }^{\mathrm{TM}} 2000$ (Invitrogen; Thermo Fisher Scientific, Inc.), according to the manufacturer's protocol.

Statistical analysis. Results are presented as the mean \pm standard deviation for three replicates. The comparison between groups was performed using one-way ANOVA, followed by Bonferroni's post hoc test. $\mathrm{P}<0.05$ was considered to indicate a statistically significant difference. 


\section{Results}

Curcumin inhibits cell proliferation of human laryngeal cancer cells. The potential anticancer effect of curcumin on cell viability of human laryngeal cancer cells was investigated. Cellular proliferation of AMC-HN-8 cells was decreased by treatment with curcumin in a dose- and time-dependent manner (Fig. 2). A dosage of between 0 and $40 \mu \mathrm{M}$ curcumin and a time of $<3$ days were used for all assays.

Curcumin increases apoptosis of human laryngeal cancer cells. To determine that the possible anticancer effect of curcumin was via apoptosis of human laryngeal cancer cells, apoptosis of AMC-HN-8 cells was determined using flow cytometry. When AMC-HN-8 cells were treated with 20 or $40 \mu \mathrm{M}$ of curcumin for 2 days, apoptosis was significantly increased compared with the untreated control cells (Fig. 3).

Curcumin increases capase-3 activity of human laryngeal cancer cells. To investigate the effect of curcumin on capase-3 activity of human laryngeal cancer cells, capase-3 activity was measured following treatment with curcumin. Curcumin at 20 and $40 \mu \mathrm{M}$ significantly increased capase- 3 activity of AMC-HN-8 cells compared with the untreated control cells (Fig. 4).

Curcumin decreases Bcl-2 protein expression in human laryngeal cancer cells. The effect of curcumin on Bcl-2 protein expression in human laryngeal cancer cells was determined using western blot analysis. Curcumin at 20 and $40 \mu \mathrm{M}$ significantly decreased the expression of Bcl-2 protein in AMC-HN-8 cells compared with the untreated control cells (Fig. 5).

Curcumin decreases $P I 3 K$ and Akt protein expression in human laryngeal cancer cells. Treatment of AMC-HN-8 cells with 20 or $40 \mu \mathrm{M}$ curcumin significantly decreased PI3K and $\mathrm{p}$-Akt protein expression, and the $\mathrm{p}$-Akt/Akt ratio was significantly decreased, compared with the untreated control cells, which revealed that curcumin induced apoptosis of laryngeal cancer via PI3K/Akt signaling pathway (Fig. 6).

Curcumin increases miR-15a expression in human laryngeal cancer cells. To determine the effect of curcumin on miR-15a expression of human laryngeal cancer cell, RT-qPCR was employed to analyze miR-15a expression in AMC-HN-8 cells. miR-15a expression was significantly increased by 20 or $40 \mu \mathrm{M}$ curcumin compared with the untreated control cells (Fig. 7).

Suppression of $\mathrm{miR}-15$ a expression partially reverses the anticancer effect of curcumin on cell proliferation of human laryngeal cancer cells. The effect of miR-15a expression on the anticancer effect of curcumin on cell proliferation of human laryngeal cancer cell was investigated. Anti-miRNA-15a significantly decreased miR-15a expression in AMC-HN-8 cells treated with $40 \mu \mathrm{M}$ curcumin, compared with $40 \mu \mathrm{M}$ curcumin $+\mathrm{NC}$ treatment (Fig. 8A). In addition, suppression of miRNA-15a expression led to a significant reversal of the anticancer effect of $40 \mu \mathrm{M}$ of curcumin on the cell inhibition rate of AMC-HN-8 cells (Fig. 8B).

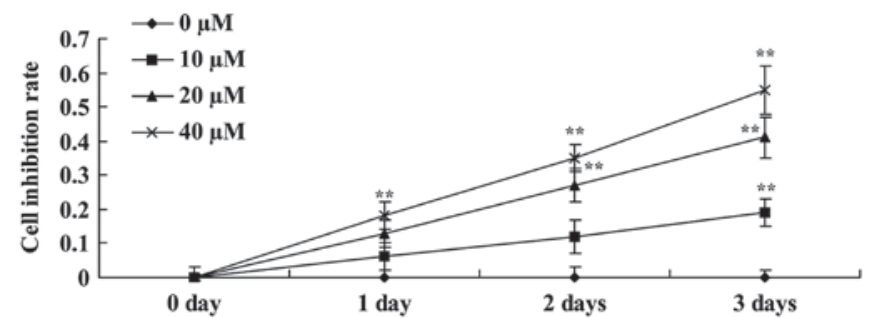

Figure 2. Curcumin inhibits the proliferation of human laryngeal cancer cells. ${ }^{* *} \mathrm{P}<0.05$ vs. untreated control cells.

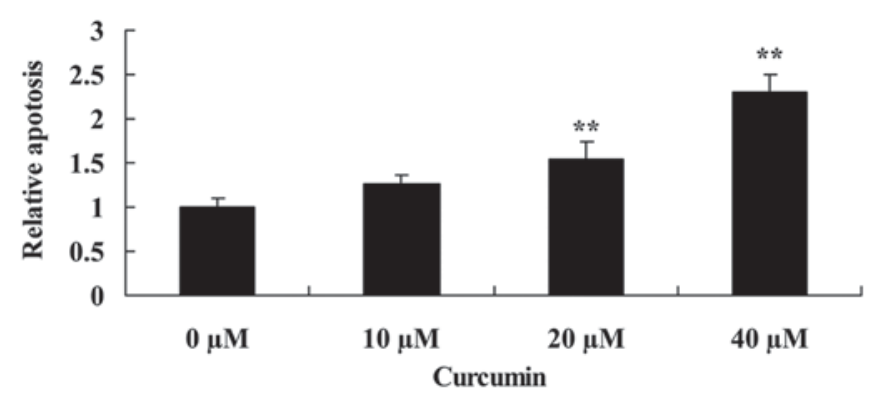

Figure 3. Curcumin promotes apoptosis of human laryngeal cancer cells. ${ }^{* *} \mathrm{P}<0.05$ vs. untreated control cells.

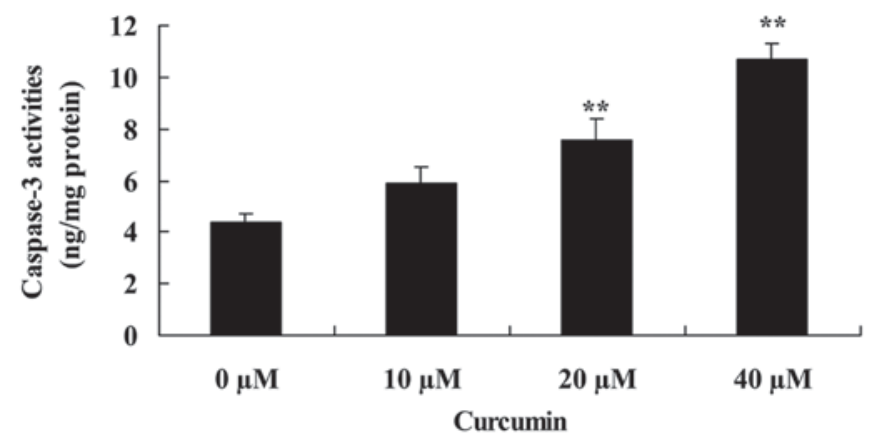

Figure 4. Curcumin promotes caspase-3 activity of human laryngeal cancer cells. ${ }^{* *} \mathrm{P}<0.05$ vs. untreated control cells.

Suppression of miR-15a expression reverses the anticancer effect of curcumin on $\mathrm{Bcl}-2, \mathrm{PI} 3 \mathrm{~K}$ and $p$-Akt protein expression in human laryngeal cancer cells. To validate the effect of suppression of miR-15a expression on the anticancer effect of curcumin on Bcl-2, PI3K and p-Akt protein expression of human laryngeal cancer cells, western blot analysis was used to analyze $\mathrm{Bcl}-2$, PI3K and p-Akt protein expression in AMC-HN-8 cells. Compared with treatment with $40 \mu \mathrm{M}$ of curcumin $+\mathrm{NC}, \mathrm{Bcl}-2$ and $\mathrm{PI} 3 \mathrm{~K}$ protein expression, and the p-Akt/Akt ratio were significantly increased by suppression of miR-15a expression in AMC-HN-8 cells treated with $40 \mu \mathrm{M}$ of curcumin (Fig. 9).

\section{Discussion}

Laryngeal caner is one of the most common types of malignant tumor in the head and neck (2). Concomitant with an increase in air pollution in recent years, the incidence of laryngeal cancer is increasing annually (4). Although it is possible to 
A

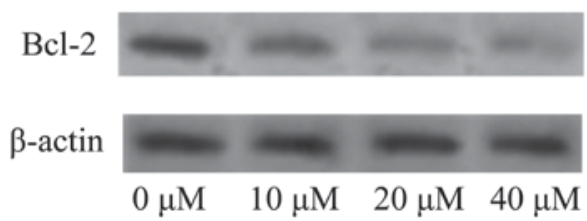

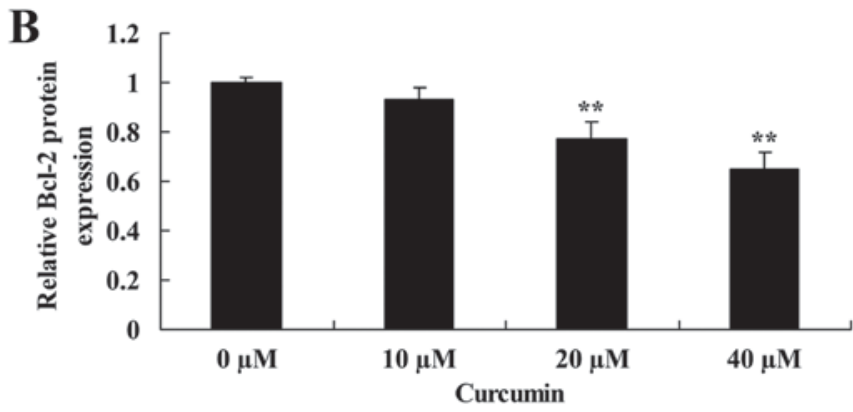

Figure 5. Curcumin decreases Bcl-2 protein expression in human laryngeal cancer cells. (A) Western blot analysis and (B) quantification of the effect of curcumin on Bcl-2 protein expression in human laryngeal cancer cells. $\beta$-actin served as a loading control. ${ }^{* *} \mathrm{P}<0.05$ vs. untreated control cells.

A

PI3K

$\beta$-actin

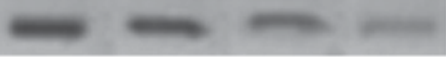

$0 \mu \mathrm{M} \quad 10 \mu \mathrm{M} \quad 20 \mu \mathrm{M} \quad 40 \mu \mathrm{M}$

C

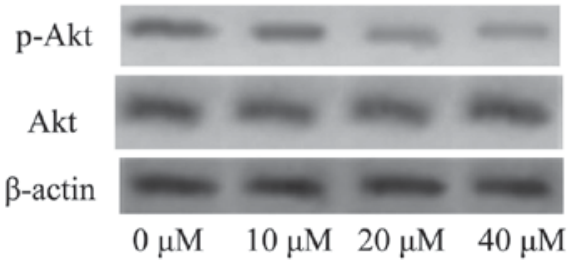

B

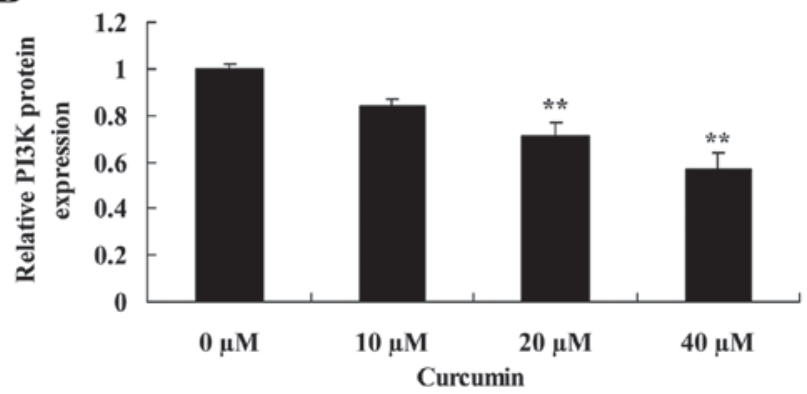

D

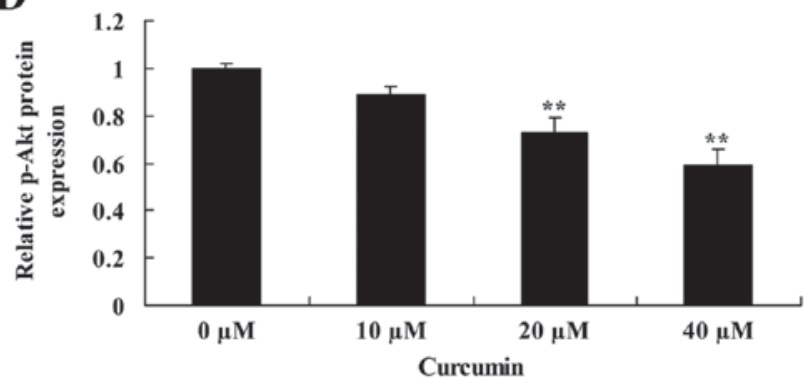

Figure 6. Curcumin decreases PI3K and p-Akt protein expression in human laryngeal cancer cells. (A) Western blot analysis and (B) quantification of the effect of curcumin on PI3K expression in human laryngeal cancer cells. $\beta$-actin served as a loading control. (C) Western blot analysis of p-Akt and Akt, and (D) quantification of p-Akt, protein expression in human laryngeal cancer cells. $\beta$-actin served as a loading control. ${ }^{* *} \mathrm{P}<0.05$ vs. untreated control cells. PI $3 \mathrm{~K}$, phosphoinositide 3-kinase; p-Akt, phosphorylated-protein kinase B.

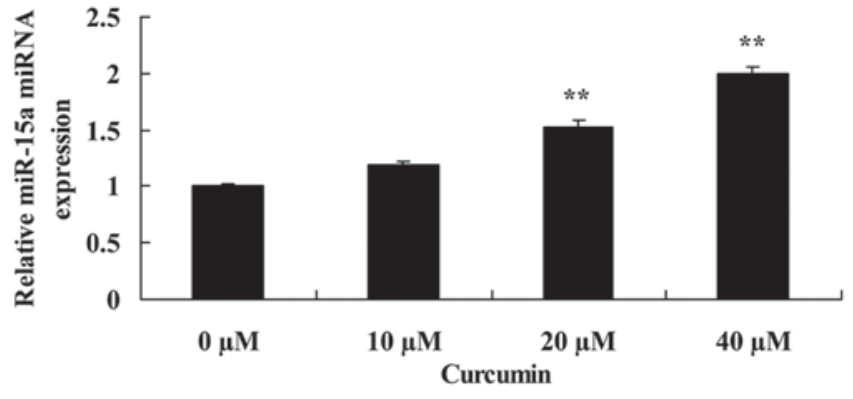

Figure 7. Curcumin increases miR-15a expression in human laryngeal cancer cells. ${ }^{* *} \mathrm{P}<0.05$ vs. untreated control cells. miR-15a, microRNA-15a.

treat the cancer using surgery, chemotherapy, radiotherapy and other treatments, a number of patients still succumbed due to local recurrence or metastasis after the radical operation, radiotherapy and chemotherapy (15). Laryngeal cancer remains a serious threat to the life and safety of patients; therefore, there is an urgent requirement to identify more effective tumor prevention and treatment (16). In the present study, it was identified that curcumin inhibits cell proliferation and promotes apoptosis of human laryngeal cancer cells. Tuorkey (17) reported that curcumin is a potent cancer preventive agent (17), and Sordillo and Helson (18) identified that curcumin exhibits asymmetrical effects on cancer and wild-type stem cells. These findings implicated curcumin as a clinically important drug for the treatment of human laryngeal cancer cells.

Apoptosis of tumor cells is a complex process involving the regulation of numerous genes, including members of the $\mathrm{Bcl}-2$ family, which are among the most important members as they are able to inhibit the apoptosis of cells (19). Bcl-2 and Bcl-extra large are able to inhibit apoptosis of cells, whereas Bcl-2-like protein (Bax) and Bcl-2 homologous antagonist/killer promote apoptosis, and alterations in expression of these genes affects the apoptosis of wild-type cells and the apoptosis of tumor cells (20). For example, expression of Bcl-2 may lead to survival of cells with damaged DNA and accumulation of 

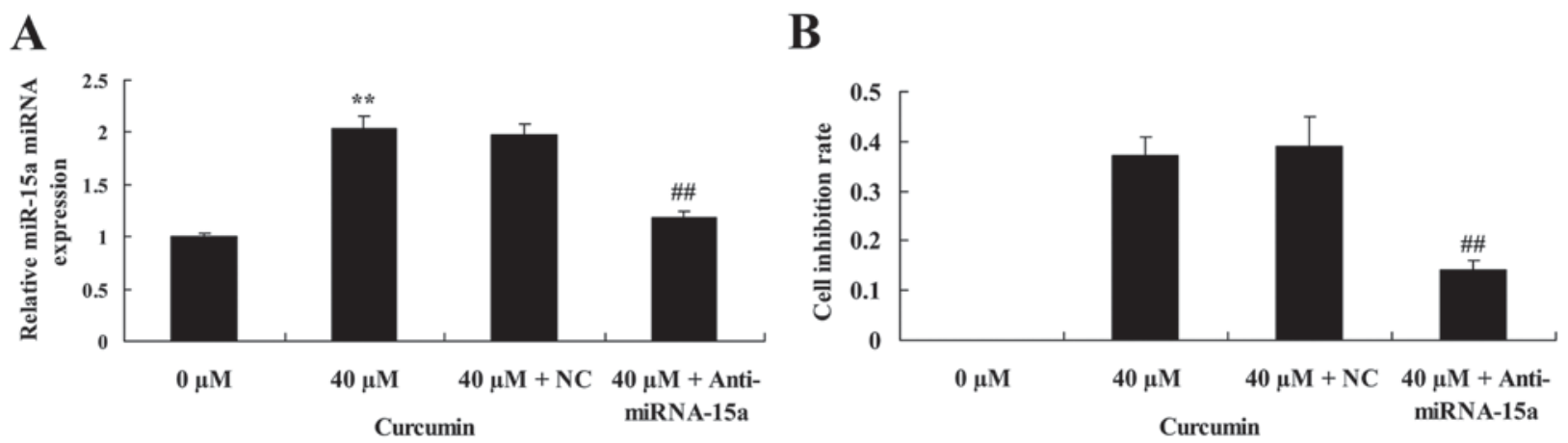

Figure 8. Suppression of miR-15a expression partially reverses the anticancer effect of curcumin on the proliferation of human laryngeal cancer cells. Suppression of miR-15a expression (A) reverses the effect of curcumin on miR-15a expression and (B) partially reverses theeffect of curcumin on cell proliferation of human laryngeal cancer cells. ${ }^{* *} \mathrm{P}<0.05$ vs. untreated control cells; ${ }^{\# \#} \mathrm{P}<0.05$ vs. cells treated with $40 \mu \mathrm{M}$ curcumin. miR-15a, microRNA-15a; NC, negative control.

A

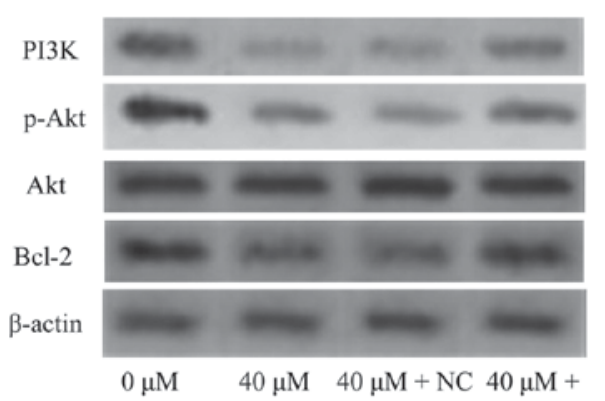

Anti-miRNA-15a

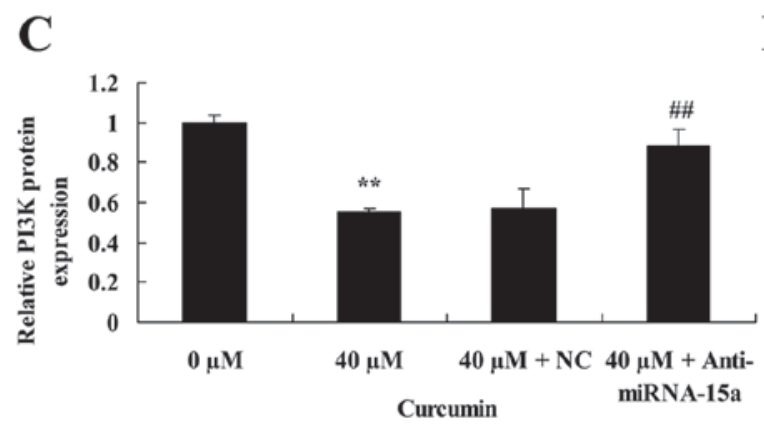

B

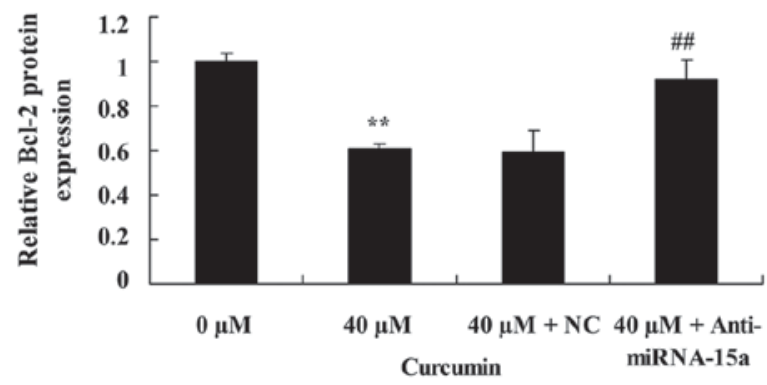

D

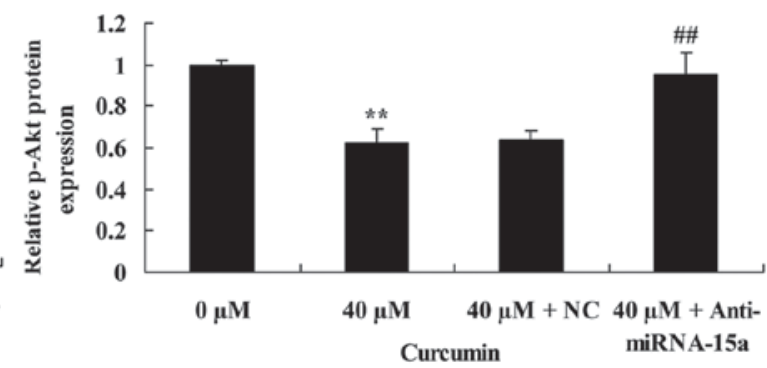

Figure 9. Suppression of miR-15a expression reverses the anticancer effect of curcumin on Bcl-2, PI3K and p-Akt protein expression of human laryngeal cancer cells. (A) Western blot analysis of the effect of curcumin on Bcl-2, PI3K, p-Akt and Akt protein expression in human laryngeal cancer cells. $\beta$-Actin was used a loading control. Quantification of (B) Bcl-2, (C) PI3K and (D) p-Akt protein expression in human laryngeal cancer cells. *** $<0.05$ vs. untreated control cells; ${ }^{\# \#} \mathrm{P}<0.05$ vs. cells treated with $40 \mu \mathrm{M}$ curcumin. miR-15a, microRNA-15a; PI3K, phosphoinositide 3-kinase; (p-) Akt, (phosphorylated-) protein kinase B; NC, negative control.

mutations, to promote tumor development (21). In the present study, curcumin was demonstrated to be able to suppress Bcl-2 protein expression in AMC-HN-8 cells. Furthermore, suppression of miR-15a expression led to an increase in Bcl-2 protein expression in AMC-HN-8 cells treated with $40 \mu \mathrm{M}$ of curcumin. Zhu et al (13) demonstrated that curcumin triggers apoptosis of SW872 human adipocytes through upregulation of caspase activation and the $\mathrm{Bax} / \mathrm{Bcl}-2$ ratio.

The PI3K/Akt signaling pathway is an important signaling pathway for growth factors in vivo, which are able to activate the anti-apoptosis mechanism, and promote the metabolism of glucose and protein synthesis, to promote the growth and proliferation of cells (7). This abnormal signal transduction pathway is able to lead to abnormal increases in cell growth, proliferation, metabolism and anti-apoptosis effect, which are involved in the development of the majority of types of tumor (22). Therefore, the PI3K/Akt signaling pathway is considered the primary pathway for the survival of cancer cells, called 'the pathway of anti-apoptosis' (23). The results of western blot analysis in the present study revealed that curcumin significantly inhibited PI3K protein expression and p-Akt protein expression in AMC-HN-8 cells treated with $40 \mu \mathrm{M}$ of curcumin. Suppression of miR-15a expression was able to reverse the effects of curcumin in AMC-HN-8 cells. Seo et al (24) reported that curcumin significantly promoted NVP-BEZ235 (a PI3K/Akt and mammalian target of rapamycin inhibitor)-induced apoptosis through Bcl-2 expression in human renal carcinoma Caki cells. Zhao et al (25) 
indicated that curcumin induces apoptosis via inhibition of the PI3K/Akt signaling pathway in pancreatic cancer cells.

miRNAs serve a negative role primarily through the inhibition of its target genes; a previous study has demonstrated that miR-15a induces the apoptosis of laryngeal carcinoma cells by activating Bcl-2 (26). It has been confirmed that miRNA-15a is able to inhibit the proliferation of laryngeal cancer cells by directly inhibiting PI3K/Akt expression (27). In the present study, it was identified that curcumin significantly increased miR-15a expression in AMC-HN-8 cells. Suppression of miRNA-15a expression significantly reversed the anticancer effect of curcumin on cell viability of AMC-HN-8 cells. Yang et al (28) reported that curcumin upregulated miR-15a and reduced the expression of Bcl-2 in MCF-7 breast cancer cells. Gao et al (29) suggested that curcumin decreases the expression of Wilms' tumor protein through miR-15a and miR-16-1 in leukemic cells. Therefore, it is hypothesized that miR-15a is able to reverse the anticancer effect of curcumin on cell viability and apoptosis of human laryngeal cancer AMC-HN-8 cells.

In conclusion, the present study demonstrates that curcumin inhibits cell proliferation and promotes apoptosis of laryngeal cancer through Bcl-2 and PI3K/Akt, and upregulating miR-15a. The results of the present study also demonstrated a functional link between miR-15a and the anticancer effect of curcumin on human laryngeal cancer cells. Further studies are required to determine the anticancer effects of curcumin on human laryngeal cancer in vivo to evaluate the potentially improved clinical significance for human laryngeal cancer in the future.

\section{References}

1. Klatka J, Grywalska E, Klatka M, Wasiak M, Andrzejczak A and Rolinski J: Expression of selected regulatory molecules on the CD83+ monocyte-derived dendritic cells generated from patients with laryngeal cancer and their clinical significance. Eur Arch Otorhinolaryngol 270: 2683-2693, 2013.

2. Gilbert K, Dalley RW, Maronian N and Anzai Y: Staging of laryngeal cancer using 64-channel multidetector row CT: Comparison of standard neck CT with dedicated breath-maneuver laryngeal CT. AJNR Am J Neuroradiol 31: 251-256, 2010.

3. Divi V, Worden FP, Prince ME, Eisbruch A, Lee JS, Bradford CR, Chepeha DB, Teknos TN, Hogikyan ND, Moyer JS, et al: Chemotherapy alone for organ preservation in advanced laryngeal cancer. Head Neck 32: 1040-1047, 2010.

4. Mouw KW, Solanki AA, Stenson KM, Witt ME, Blair EA, Cohen EE, Vokes EE, List M, Haraf DJ and Salama JK: Performance and quality of life outcomes for T4 laryngeal cancer patients treated with induction chemotherapy followed by chemoradiotherapy. Oral Oncol 48: 1025-1030, 2012.

5. Ampil FL and Nguyen NP: Defining 'upper mediastinal irradiation' in secondary subglottic laryngeal cancer. Oral Oncol 50 e15-e16, 2014

6. Janssens GO, van Bockel LW, DoornaertPA, Bijl HP, van den EndeP, de Jong MA, van den Broek GB, Verbist BM, Terhaard CH, Span PN and Kaanders JH: Computed tomography-based tumour volume as a predictor of outcome in laryngeal cancer: Results of the phase 3 ARCON trial. Eur J Cancer 50: 1112-1119, 2014.

7. Vachhani P, Bose P, Rahmani M and Grant S: Rational combination of dual PI3K/mTOR blockade and $\mathrm{Bcl}-2 /-\mathrm{xL}$ inhibition in AML. Physiol Genomics 46: 448-456, 2014.

8. Yu X and Li Z: The role of MicroRNAs expression in laryngeal cancer. Oncotarget 6: 23297-23305, 2015.

9. Zhang Y, Chen Y, Yu J, Liu G and Huang Z: Integrated transcriptome analysis reveals miRNA-mRNA crosstalk in laryngeal squamous cell carcinoma. Genomics 104: 249-256, 2014.

10. Wu W, Geng H, Liu Z, Li H and Zhu Z: Effect of curcumin on rats/mice with diabetic nephropathy: A systematic review and meta-analysis of randomized controlled trials. J Tradit Chin Med 34: 419-429, 2014
11. Koprowski S, Sokolowski K, Kunnimalaiyaan S, Gamblin TC and Kunnimalaiyaan M: Curcumin-mediated regulation of Notch1/hairy and enhancer of split-1/survivin: Molecular targeting in cholangiocarcinoma. J Surg Res 198: 434-440, 2015.

12. He Y, Yue Y, Zheng X, Zhang K, Chen S and Du Z: Curcumin, inflammation and chronic diseases: How are they linked? Molecules 20: 9183-9213, 2015.

13. Zhu L, Han MB, Gao Y, Wang H, Dai L, Wen Y and Na LX: Curcumin triggers apoptosis via upregulation of $\mathrm{Bax} / \mathrm{Bcl}-2$ ratio and caspase activation in SW872 human adipocytes. Mol Med Rep 12: 1151-1156, 2015.

14. Zubillaga-Guerrero MI, Alarcón-Romero Ldel C, Illades-Aguiar B, Flores-Alfaro E, Bermúdez-Morales VH, Deas J and PeraltaZaragoza O: MicroRNA miR-16-1 regulates CCNE1 (cyclin E1) gene expression in human cervical cancer cells. Int J Clin Exp Med 8: 15999-16006, 2015.

15. Koskinen WJ, Brøndbo K, Mellin Dahlstrand H, Luostarinen T, Hakulinen T, Leivo I, Molijn A, Quint WG, Røysland T, Munck-Wikland E, et al: Alcohol, smoking and human papillomavirus in laryngeal carcinoma: A Nordic prospective multicenter study. J Cancer Res Clin Oncol 133: 673-678, 2007.

16. Hamilton DW, de Salis I, Donovan JL and Birchall M: The recruitment of patients to trials in head and neck cancer: A qualitative study of the EaStER trial of treatments for early laryngeal cancer. Eur Arch Otorhinolaryngol 270: 2333-2337, 2013.

17. Tuorkey MJ: Curcumin a potent cancer preventive agent: Mechanisms of cancer cell killing. Interv Med Appl Sci 6: 139-146, 2014.

18. Sordillo PP and Helson L: Curcumin and cancer stem cells: Curcumin has asymmetrical effects on cancer and normal stem cells. Anticancer Res 35: 599-614, 2015.

19. Hosseini A, Sharifi AM, Abdollahi M, Najafi R, Baeeri M, Rayegan S, Cheshmehnour J, Hassani S, Bayrami Z and Safa M: Cerium and yttrium oxide nanoparticles against lead-induced oxidative stress and apoptosis in rat hippocampus. Biol Trace Elem Res 164: 80-89, 2015.

20. Besbes S, Mirshahi M, Pocard M and Billard C: New dimension in therapeutic targeting of BCL-2 family proteins. Oncotarget 6: 12862-12871, 2015.

21. Moldoveanu T, Follis AV, Kriwacki RW and Green DR: Many players in BCL-2 family affairs. Trends Biochem Sci 39: 101-111, 2014.

22. Bitting RL and Armstrong AJ: Targeting the PI3K/Akt/mTOR pathway in castration-resistant prostate cancer. Endocr Relat Cancer 20: R83-R99, 2013.

23. Simpson DR, Mell LK and Cohen EE: Targeting the $\mathrm{PI} 3 \mathrm{~K} / \mathrm{AKT} / \mathrm{mTOR}$ pathway in squamous cell carcinoma of the head and neck. Oral Oncol 51: 291-298, 2015.

24. Seo BR, Min KJ, Cho IJ, Kim SC and Kwon TK: Curcumin significantly enhances dual PI3K/Akt and mTOR inhibitor NVP-BEZ235-induced apoptosis in human renal carcinoma Caki cells through down-regulation of p53-dependent Bcl-2 expression and inhibition of Mcl-1 protein stability. PLoS One 9: e95588, 2014

25. Zhao Z, Li C, Xi H, Gao Y and Xu D: Curcumin induces apoptosis in pancreatic cancer cells through the induction of forkhead box O1 and inhibition of the PI3K/Akt pathway. Mol Med Rep 12: 5415-5422, 2015

26. Li L, Zhang ZM, Liu Y, Wei MH, Xue LY, Zou SM, Di XB, Han NJ, Zhang KT, Xu ZG and Gao YN: DNA microarrays-based microRNA expression profiles derived from formalin-fixed paraffin-embedded tissue blocks of squammous cell carcinoma of larynx. Zhonghua Bing Li Xue Za Zhi 39: 391-395, 2010 (In Chinese).

27. Skawran B, Steinemann D, Becker T, Buurman R, Flik J, Wiese B, Flemming P, Kreipe H, Schlegelberger B and Wilkens L: Loss of $13 \mathrm{q}$ is associated with genes involved in cell cycle and proliferation in dedifferentiated hepatocellular carcinoma. Mod Pathol 21: 1479-1489, 2008.

28. Yang J, Cao Y, Sun J and Zhang Y: Curcumin reduces the expression of Bcl-2 by upregulating miR-15a and miR-16 in MCF-7 cells. Med Oncol 27: 1114-1118, 2010.

29. Gao SM, Yang JJ, Chen CQ, Chen JJ, Ye LP, Wang LY, Wu JB, Xing CY and Yu K: Pure curcumin decreases the expression of WT1 by upregulation of miR-15a and miR-16-1 in leukemic cells. J Exp Clin Cancer Res 31: 27, 2012. 